\title{
LA CRISIS AMBIENTAL Y LOS DERECHOS DE LA NATURALEZA: UNA VISIÓN DESDE LA ECOLOGÍA POLÍTICA
}

\author{
ENVIRONMENTAL CRISIS AND THE RIGHTS OF NATURE: A VIEW FROM THE \\ POLITICAL ECOLOGY
}

Elizabeth Bravo

Escuela de Gestión para el Desarrollo Local Sostenible. Universidad Politécnica Salesiana. Av. 12 de Octubre N24-22 y Wilson. Telf. (593-3) 3962 800, Quito, Ecuador

Autor para correspondencia: elizabethbravovelasquez@yahoo.com

Manuscrito recibido el 1 de febrero de 2013. Aceptado, tras revisión, el 7 de mayo de 2013.

\begin{abstract}
Resumen
La crisis ambiental indicada durante la Revolución Industrial y agudizada a partir del último quinquenio del siglo XX, ha producido cambios tan profundos en el planeta; lo que la levaría a enfrentar una nueva era geológica: el Antropoceno. La extracción de recursos naturales y la movilización de materiales y energía ha respondido a una economía de rapiña por parte de los países industrializados hacia sus excolonias. Por tal motivo, el derecho humano a un medio ambiente sano y libre de contaminación ya no es suficiente, como tampoco lo es el concepto de desarrollo sustentable. En ese sentido, la Constitución del Ecuador hace una propuesta radical cuando reconoce derechos a la naturaleza y establece que es el Sumak Kawsay el camino por donde debemos transitar para mejorar la relación con nuestro medio. Esto implica que las actividades económicas deben respetar el derecho al mantenimiento y regeneración de los ciclos vitales, estructura, funciones y procesos evolutivos de la naturaleza.
\end{abstract}

Palabras claves: derechos de la naturaleza, sumak kawsay, antropoceno, metabolismo social, mantenimiento de ciclos biológicos y evolutivos.

\begin{abstract}
The environmental crisis that began during the Industrial Revolution and that has worsened since the last 50 years of the XX Century, has produced deep changes in the Planet. It has being proposed that we are facing a new geological era: the Anthropocene. The extraction of natural resources and the mobilization of materials and energy is the result of a predatory economy of the industrialized countries to their ancient colonies. In this context, the human right to a healthy environment and free from pollution is not enough, nor is the concept of sustainable development. In that sense, the Constitution of Ecuador made a radical change, when it recognizes rights to nature and makes the Sumak Kawsay the road that we must transit to improve our relationship with our environment. This implies that economic activities must respect the right of the maintenance and regeneration of the vital cycles, structure, functions and evolutionary processes of nature.
\end{abstract}

Keywords: nature rights, sumak kawsay, antropocene, social metabolism.

Forma sugerida de citar: Bravo, E. 2013. La crisis ambiental y los derechos de la naturaleza: una visión desde la ecología política. La Granja. Vol. 17(1): 44-52. ISSN: 1390-3799. 


\section{Introducción}

Desde inicios del siglo XX, se ha venido gestando una crisis ambiental sin precedentes, pero esta se ha hecho más evidente en las últimas décadas, lo que ha obligado a cambiar la agenda de investigación y de preocupación de los estados y los movimientos sociales, como lo señala Naredo (2008) hablando sobre el tema energético:

El problema del agotamiento del petróleo fue una preocupación generalizada en la década de los setenta. Las "crisis petrolíferas" de 1973 y 1979, motivadas por la elevación de los precios del crudo promovidas por los países de la OPEP, propiciaron este tipo de reflexiones que llevaron a vaticinar que la civilización industrial colapsaría, sobre todo por escasez de recursos. Sin embargo, treinta años después, cuando el consumo global de energía ha amentado en más de un $70 \%$ y cuando hay mucho menos petróleo extraíble en la corteza terrestre del que había entonces, ya no preocupa tanto su escasez como el "cambio climático" derivado del exceso de residuos.

Las primeras preocupaciones sobre la crisis ambiental a nivel internacional se dieron durante la Cumbre de Estocolmo en 1972, sobre la que Muria (2012) destaca dos proclamas:

(Proclama 5): de todas las cosas del mundo, los seres humanos son lo más valioso. Ellos son quienes promueven el progreso social, crean riqueza social, desarrollan la ciencia y la tecnología y, con su duro trabajo, transforman continuamente el medio humano.

(Proclama 4): en los países en desarrollo, la mayoría de los problemas ambientales están motivados por el subdesarrollo (...), en los países industrializados, los problemas ambientales están generalmente relacionados con la industrialización y el desarrollo tecnológico ${ }^{1}$.

$Y$ concluye que aunque el derecho ambiental tiene muy poco que ver con la protección ambiental, un ambiente sano es importante en la medida en que se garantiza una calidad de vida para las poblaciones humanas ${ }^{2}$.

Posteriormente, en la Cumbre de Río se establece la necesidad de una institucionalidad desde los Estados para enfrentar los temas ambientales, y se cuaja el "término de desarrollo sustentable" que establece la necesidad de un desarrollo que contemple las necesidades de las futuras generaciones, y que sea a la vez justo, ecológicamente equilibrado y económicamente sostenible. Como resultado de esta cumbre, se crean Ministerios o Secretarías del Ambiente, consejos de desarrollo sustentable, y se dictan normas ambientales en todo el mundo.

Diez años más tarde, en la Cumbre de Johannesburgo (conocida como Río +10 ) se propone como vía para alcanzar el desarrollo sustentable el establecimiento de "Asociaciones Público-Privadas". Los Estados de los países miembros de la OCDE empezaron a desviar los fondos destinados a la "ayuda al desarrollo" para promover proyectos de "desarrollo sustentable" a través de sus empresas.

Pero, el desarrollo sustentable no llegó y es así como en el 2012 en la Cumbre Río + 20 se promueve el llamado "Capitalismo Verde" como el camino para la sustentabilidad; esto quiere decir, el desarrollo sustentable en manos de las empresas.

Una vía muy distinta es la que decidió tomar el Ecuador, cuando en su Constitución del 2008 reconoció derechos a la naturaleza, transformándola en portadora de los mismos; lo que estableció un hito en la legislación universal.

La Constitución del Ecuador, en su preámbulo celebra "a la naturaleza, la Pacha Mama, de la cual somos parte y que es vital para nuestra existencia" y se decide construir:

Una nueva forma de convivencia ciudadana,
en diversidad y armonía con la naturaleza,
para alcanzar el buen vivir, el sumak kawsay
(Preámbulo Constitución del Ecuador).

Es decir, se supera inclusive el concepto de "desarrollo" por el "Buen Vivir" o "Sumak Kaw-

\footnotetext{
${ }^{1}$ Conferencia de las Naciones Unidas sobre Medio Ambiente. Declaración de Estocolmo. 1972.

${ }^{2}$ Para profundizar los aspectos legales de los derechos de la naturaleza ver. Murcia, D. 2012. La Naturaleza con Derechos. Instituto de Estudios Ecologistas. Quito.
} 
say", en el que los derechos de la naturaleza son parte constitutiva.

\section{2. ¿Por qué ahora son necesarios los derechos de la naturaleza?}

El reconocimiento de los derechos de la naturaleza surgen ante la necesidad de protegerla, dado que los cambios que se han producido en el mundo natural son muy profundos. Propuesto primero por Paul Crutzen, sostiene que las actividades humanas han alterado tanto al planeta que estamos frente a una nueva era geológica, el Antropoceno. Ramón Fernández Durán desarrollando los postulados de Crutzen señala que:

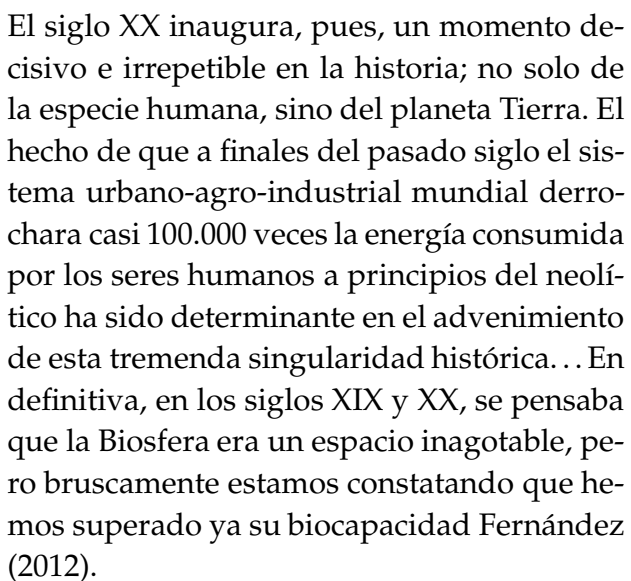

Para 1995, la sociedad urbano-agro-industrial movilizó 104 mil millones de toneladas de materiales y energía diversos (biomasa, rocas y minerales), incluyendo 12 veces más de plomo; 8,5 veces más de molibdeno y 24 veces de cobre, que lo que moviliza la naturaleza través de sus ciclos bio-geo-químicos.

Para el Centro sobre la Resiliencia de la Universidad de Estocolmo, hemos llegado a este estado por la difusión en mayor o menor medida de la civilización urbano-agraria industrial hasta los rincones más apartados del Planeta (citado en Ruiz, 2012). En 2009, un grupo de 28 científicos liderados por este Centro, identificaron nueve fronteras planetarias dentro de las cuales la humanidad pueda continuar desarrollándose y prosperando para las generaciones venideras. Ellos sostienen que si se pasa es-

\footnotetext{
${ }^{3}$ Más información sobre estas fronteras pueden encontrarse -programmes/planetary-boundaries.html $\rangle$.
}

tos límites, se podrían generar cambios ambientales abruptos o irreversibles. Estas barreras son:

1. cambios climáticos,

2. extinción de las especies y la erosión de la biodiversidad,

3. acumulación de nitrógeno en la biosfera,

4. contaminación química,

5. acidificación de los océanos,

6. cambios en el flujo del fósforo,

7. carga de aerosoles en la estratosfera (que conduce a la erosión de la capa de ozono),

8. cambios en el uso de la tierra, sobre todo para la agroindustria,

9. contaminación química,

10. sobrexplotación y contaminación del agua dulce.

Ellos sostienen que los tres primeros ya han sobrepasado los límites de resiliencia del Planeta; lo más grave es la pérdida de biodiversidad. En cuanto a las 4 últimas fronteras, estas se acercan peligrosamente a estos límites ${ }^{3}$.

En resumen, las principales formas de degradación de la naturaleza podrían agruparse en los siguiente grupos:

- Agotamiento de la biodiversidad, de los recurso pesqueros, madera y agua limpia.

- Destrucción de la capacidad de regeneración de los ciclos biofísicos.

- La contaminación de diversos tipos: química, electromagnética, biológica y genética.

- Transformación de los ecosistemas en otras formas de uso.

Visto de otra manera, el deterioro del mundo natural está ligado a la forma como las sociedades a través de los sistemas económicos imperantes- se relacionan con la naturaleza. Mediante estos no solamente se "extrae" agua, materiales y energía de la naturaleza, sino que se introducen nuevos elementos y se producen desechos, generando un flujo de en 〈http://www.stockholmresilience.org/21/research/research LA GRANJA, Revista de Ciencias de la Vida, 17(1) 2013: 44-52.

(C) 2013, Universidad Politécnica Salesiana, Ecuador. 
materiales y energía que entran y sale del sistema productivo, influyendo distintos tipos de impactos en la naturaleza y transformaciones en el propio ser humano. Estos flujos de materiales y energías son necesarios para que las sociedades humanas produzcan y reproduzcan sus condiciones materiales de existencia a partir de su metabolismo con la naturaleza o metabolismo social (Altvater, 2012). Sobre el metabolismo social, Toledo (2008) señala que:

(...) dicho fenómeno implica el conjunto de procesos por medio de los cuales los seres humanos organizados en sociedad, independientemente de su situación en el espacio (formación social) y en el tiempo (momento histórico), se apropian, circulan, transforman, consumen y excretan, materiales y/o energías provenientes del mundo natural.

El concepto de metabolismo social fue desarrollado por Marx desde sus primeros escritos, pero fue desarrollado como un fenómeno físico (en el que se pueden medir los flujos de energía y materiales) por Nicholas Georgescu-Roegen en la segunda mitad del siglo XX (Martínez, 2008).

Georgescu-Roegen sostiene que si bien las sociedades humanas siempre han dependido de flujos de energía y materiales, ahora ha cambiado la escala de estos. Entre mayores son los flujos de energía y materiales en un sistema productivo, y entre mayor sea la cantidad de desechos que genere, mayor será la brecha del metabolismo entre la sociedad y la naturaleza. Del mismo modo, si hay un creciente flujo de materiales y energía que salen del sistema (por ejemplo como exportaciones), y no son utilizados in situ (es decir para el consumo local o regional), la brecha también aumentará.

A lo largo de la historia, el metabolismo socioambiental de las sociedades ha sido distinto, alcanzado la brecha más grande en la última mitad del siglo XX e inicios del XXI; lo que ha significado una mayor degradación de la naturaleza. De igual manera, en un mismo período histórico el metabolismo social varía de acuerdo a la clase social, la etnia y la ubicación geopolítica de una nación. Los países del llamado "mundo occidental" han desarrollado sus economías con base a la extracción de los "recursos naturales" de otras regiones del mundo.

Alimonda (2012) abonando a este debate señala que la subordinación colonial de pueblos y de la naturaleza es una condición necesaria para la repro- ducción del régimen de producción del capitalismo, como lo había expresado ya Rosa Luxemburgo. Para ella, la colonialidad es parte constituyente de la acumulación de capital, es su reverso fundante y necesario. En sus escritos sobre "La acumulación de capital" Rosa dice:

Este proceso se desarrolla en la escena mundial. Aquí reinan, como métodos, la política colonial, el sistema de empréstitos internacionales, la política de intereses privados y la guerra. Aparecen aquí, sin disimulo, la violencia, el engaño, la opresión, la rapiña (Luxemburgo, 1967).

Foster y Clark (2004) van más allá cuando se refieren al imperialismo ecológico

El control de dichos flujos (materiales y energía) es una parte vital de la competencia entre centros industriales y financieros rivales. Por lo tanto, el imperialismo ecológico se presenta de diversas maneras, mediante el saqueo de recursos de ciertos países por otros y la consiguiente transformación de ecosistemas enteros de los cuales estados y naciones dependen; movimientos masivos de trabajo y poblaciones vinculadas a la extracción y transferencia de recursos; la explotación de las vulnerabilidades ecológicas de ciertas sociedades para promover un mayor control imperial; la descarga de desechos ecológicos que amplían la brecha entre el centro y periferia; y en conjunto, la creación de una "discontinuidad metabólica" global.

Este colonialismo ha generado una economía de rapiña, de la que Joan Martínez Alier (2008) dice:

Esta se define como la importación de productos de países pobres a precios que no tienen en cuenta el agotamiento de los recursos ni las externalidades negativas locales.

Así, podemos identificar dos grandes grupos de actividades en las que se sustenta esta economía de rapiña:

- la extracción minera, de petróleo, gas y carbón, pero también de madera, pesca y biodiversidad,

- los monocultivos que extraen minerales y agua y se exportan en forma de agua virtual. 
La rapiña europea en América Latina durante la colonia se centró en la explotación minera (especialmente de oro y en menor medida de palta), y en la economía de plantaciones. La extracción de minerales transformó tanto a las sociedades como a la naturaleza americana, como lo señala Vitali (1983) al referirse a las explotaciones mineras en Potosí o a los monocultivos de cacao, azúcar o algodón, poniendo a los ecosistemas originarios en un estado de alta vulnerabilidad. Reinaldo Funes (2009) también describe cómo la expansión de las plantaciones de caña de azúcar en Cuba, transformó los ecosistemas de la isla de manera irreversible, y fue la principal causa de deforestación ${ }^{4}$.

Esta tendencia se mantiene después de la independencia, pues los países de América Latina mantuvieron relaciones coloniales con Europa, especialmente con Inglaterra. Se estableció una división internacional del trabajo, acelerada por la Revolución Industrial donde le tocó a nuestros países ser proveedores de materia prima básica basada en la mono-producción de productos agrícolas o minerales, y se aceleró la devastación de los bosques (Vitali, 1983).

Este es un modelo que se mantiene hasta nuestros días, pues muchos de los países latinoamericanos somos exportadores de productos extraídos de la naturaleza (minerales, hidrocarburos, madera o peces) o de productos agrícolas para cubrir las necesidades de otros países, bajo el control de grandes empresas transnacionales ${ }^{5}$.

Con la crisis del capital financiero, la economía de rapiña podría auxiliar a la resquebrajada economía europea y estadounidense por medio de valorizarla a través del control de los commodities agrícolas y mineros provenientes del Tercer Mundo; por eso están aumentando las concesiones mineras en toda América Latina, así como los monocultivos. No importa dónde se produzcan o extraigan ni dónde se consuman; lo que importa es quién los controla. En esa necesidad de control se baten empresas nacionales y transnacionales. Pero la necesidad de crecimiento de esta economía es tal, que crece a un ritmo distinto del ritmo de regeneración de los ciclos biofísicos de la naturaleza (Ruiz, 2012).

Esta sociedad urbano-agro-industrial que abrió el camino para el surgimiento del antropoceno, tie- ne como base ideológica el pensamiento moderno, que es el complemento de la colonialidad (Escobar, 2003), sustentado por una ciencia y una tecnología puesta a su servicio.

La aplicación de esta racionalidad al mundo, en un contexto colonial, transformó el planeta y toda su diversidad en el que convivían animales, plantas, agua, seres humanos, agua; en abstracciones matemáticas. El pensamiento moderno imperial, que nos ha llevado a una crisis ambiental sin precedentes, mira a la naturaleza como un objeto, medible, modificable, puede ser por lo tanto también dominada, privatizada y mercatilizada (Porto Gonçalves, 2002).

Es este escenario en el que nacen los dos grandes nuevos paradigmas de la Constitución del Ecuador: los derechos de la naturaleza y el buen vivir.

\section{Los derechos de la naturaleza}

La Constitución del Ecuador, al desarrollar el contenido de los derechos de la naturaleza, sostiene que, si bien reconoce que las personas, comunidades, pueblos y nacionalidades tienen derecho a beneficiarse del ambiente y de las riquezas naturales que les permitan el buen vivir (Art. 74), se deben mantener su estructura y funciones, se debe respetar sus ciclos evolutivos y procesos biológicos y en caso de daños, se debe hacer una restauración integral (Art. 71).

El desarrollo teórico de los derechos de la naturaleza es un campo aun en disputa. Por un lado están las estrategias conservacionistas que tiende a ver el todo en partes fragmentadas. Basándose en información como número de un determinado grupo taxonómico de importancia como las llamadas "especies paradigmáticas" (por ejemplo mamíferos acuáticos, grandes carnívoros o especies endémicas en peligro) desarrollan propuestas de zonificación territorial en las cuales hay áreas para el desarrollo industrial (minero, petrolero, agroexportador, etc.) y otras zonas destinadas a la conservación. En estas últimas, gran parte del esfuerzo y los recursos van para su preservación, las mismas que están al servicio del disfrute humano.

\footnotetext{
${ }^{4}$ Eduardo Galeano en su libro "Las venas abiertas de América Latina" y en otras de sus publicaciones da cuenta de estas historias.

${ }^{5}$ El grupo ETC publica periódicamente información sobre el control corporativo sobre las llamadas "industrias de la vida". Su último informe “¿Quién controlará la economía verde?” (2011) está disponible en 〈www.etcgroup.org
} 
Otra forma de abordar los problemas ambientales en general y, ahora, los derechos de la naturaleza, parte de un paradigma tecnocrático; es decir en la aplicación de instrumentos de la ciencia y la tecnología o la aplicación de normas y estándares ambientales. Trabajan mucho con los sistemas de manejo ambiental (planes de manejo, evaluación de riesgos, etc.) sin cuestionar las estructuras sociales y políticas, ni los modelos económicos causantes del deterioro ambiental (Peet y Watts, 1996).

Desde la economía ambiental, se ve la naturaleza como un bien o un servicio que puede ser transformado en mercancía. Desde este paradigma, la naturaleza cumple una serie de funciones (para beneficio del ser humano), como son la regulación climática, el control de la erosión, la polinización, la dispersión de semillas y el almacenamiento de agua. El paisaje de algunos ecosistemas nos sirven de deleite y recreación, y los arrecifes de coral y manglares constituyen el sitio de apareamiento y desove de la mayoría de peces con valor comercial en mares tropicales.

Esta visión sobre las "funciones ecológicas" ha llevado a la confusión de que la naturaleza provee "servicios" y que estos servicios pueden ser mercantilizados. La concepción de "servicios ambientales" o "servicios de la naturaleza" reduce el valor de esta última a la utilidad y servidumbre que podrían tener para una actividad humana concreta, sin tomar en cuenta su valor ontológico. Por supuesto, en un marco de capitalismo liberal todo servicio es una mercancía y, por lo tanto, se puede privatizar. Lamentablemente en nuestra Constitución, se reconoce que las funciones de la naturaleza pueden ser transformadas en servicios a los que se da el mismo tratamiento de los recursos naturales no renovables, es decir están protegidos y regulados por el Estado, pero pudiendo ser explotados en asociación con las empresas privadas (Art. 74). Dado que las funciones de la naturaleza ${ }^{6}$ son tan vitales para la vida de la gente, este texto constitucional es violatorio de los derechos humanos.

Otro paradigma para entender los derechos de la naturaleza es el del Sumak Kawsay -un concepto de la cosmovisión andina- el cual plantea que los seres humanos tienen una forma de relacionamiento con otros seres humanos y con la naturaleza, basados en cuatro principios:
- La relacionalidad, que sostiene que no puede haber ningún "ente" (seres humanos, naturaleza y a los seres divinos) carente de relaciones, por eso hay que proteger la vida en comunidad.

- La correspondencia, que es una relación mutua y bidirecional entre los campos de la realidad: simbólico, cualitativo, celebrativo, ritual y afectivo. Los distintos aspectos de la realidad se corresponden de manera armoniosa.

- La complementariedad que sostiene que todo ente o acción coexiste con su complemento específico y no puede existir de manera particular.

- La reciprocidad que dice a cada acto corresponde un acto recíproco, como una contribución complementaria (Estermann, 1998).

Desde esta racionalidad, los derechos de la naturaleza (el mantenimiento de su estructura y funciones, de sus ciclos evolutivos y naturales) están relacionados entre sí, porque al cambiar la estructura de alguno de los elementos de la naturaleza, están cambiando sus funciones; lo que puede tener efectos en los procesos evolutivos y repercutir en los procesos biológicos.

Tomemos por ejemplo la unidad autónoma más pequeña que hay en la naturaleza: el átomo. Cuando se descubrió su estructura y se procedió a cambiarla (a través de la fisión nuclear), se cambiaron también sus funciones, pues en este proceso se genera gran cantidad de energía. Tanto su aplicación militar (por ejemplo en Hiroshima y Nagasaki) como los graves accidentes ocurridos en la generación de energía (Chernóbil, Fukushima), han provocado daños irreversibles en la naturaleza. A esto hay que sumar las implicaciones de la minería de uranio, las pruebas nucleares en el Pacífico... En cualquiera casos, su uso produce alteraciones en los ciclos biológicos y evolutivos.

Las estructuras vivas más pequeñas son las moléculas. Con la ingeniería genética, la nanobiotecnología, la biología sintética y otras técnicas modernas, se está alterado la estructura del ADN, que es la primera molécula capaz de auto replicarse y de la que dependen gran parte de las funciones biológicas. El

\footnotetext{
${ }^{6}$ Para mayor información sobre los servicios ambientales, ver Contanza et al. 1997. "The value of the world's ecosystem services and natural capital". Nature. 387, 253-260 (15 mayo 1997).
} 
cambio en la secuencia de los genes (en su estructura), produce también cambios es su funcionamiento; lo que conlleva a disfunciones graves en la naturaleza en general. La tecnología del ADN recombinante ha generado cultivos transgénicos diseñados para que sean resistentes a herbicidas. Esto ha conducido a que hoy hayan en el mundo millones de hectáreas de soya y maíz sobre los que se rocían millones de toneladas de herbicidas, lo que afecta a otros niveles de la naturaleza, como son los microorganismos del suelo y del agua, las plantas e insectos que juegan roles claves en las cadenas alimenticias, sin mencionar el efecto en la salud de los trabajadores agrícolas, de las poblaciones que viven cercanas a las plantaciones y de los consumidores.

La nanotecnología altera la estructura de las moléculas para producir nuevos materiales, que tienen funciones totalmente distintas a sus elementos constitutivos originales. Este es el caso de materiales como el grafeno, que es un alótropo del Carbono formando nanotubos, usado en circuitos integrados o como aditivos para materiales compuestos y como sistemas de pruebas de laboratorio en física del estado sólido. Los impactos en el ambiente y salud aún son poco entendidos, pero dado su reducido tamaño, estas nuevas composiciones moleculares son capaces de penetrar los poros de las células y los poros de la pared nuclear, produciendo mutaciones en todos los seres vivos que entren en contacto con estos materiales ${ }^{7}$, y por lo mismos en sus procesos evolutivos.

Varias actividades económicas alteran la estructura de los ecosistemas (y con ello sus funciones), es la minería la más radical, pues destruye toda la capa vegetal hasta llegar a la formación geológica que contiene el mineral con importancia comercial, pulveriza la roca y separa el mineral. Todas estas fases de la extracción minera usan grandes cantidades de energía y generan montañas de desechos. Lo que queda del ecosistema original es un sitio asolado donde impera un paisaje lunar.

Los cambios de la estructura y funciones de la naturaleza no se limitan al ambiente que nosotros habitamos: la biosfera. Con el desarrollo de la tec- nología al servicio del capital, se ha podido llegar a lugares del Planeta donde antes era impensable y la naturaleza ha reaccionado. Este fue el caso del mayor derrame petrolero ocurrido en Estados Unidos, producido por una explosión ocurrida en una plataforma petrolera de la empresa BP, cuando se hallaba buscando hidrocarburos en aguas super profundas en el Golfo de México ${ }^{8}$.

Otro campo en disputa es la forma como a de entenderse el mantenimiento de los procesos evolutivos. A lo largo del siglo XX, prevaleció la noción darwinista/malthusiana de la evolución que sostiene que esta está determinada por la mano invisible de la "selección natural" y la "sobrevivencia de los más aptos" en una lucha en la que hay recursos escasos. Esta teoría, más tarde recreada bajo el Neodarwinismo o síntesis moderna -que establece el matrimonio entre la genética de Mendel como base de la herencia biológica y la teoría de la evolución de Darwin- marcó el camino que seguiría la biología (y otras disciplinas relacionadas como la agricultura y la medicina) en el siglo $X X^{9}$.

La síntesis moderna dice que las mutaciones genéticas aleatorias son la principal fuente de variabilidad, y estas mutaciones pueden ser positivas (o adaptativas) y por lo mismo "seleccionadas" (es decir le otorgan a su portador la capacidad de dejar descendencia fértil, de transmitir sus genes a las siguientes generaciones), o pueden ser negativas y por lo mismo eliminadas por la selección natural.

El Neodarwinismo establece que un carácter está controlado por un gen que le confiere a un organismo una ventaja (o desventaja) adaptativa; explica, así, cada uno de los caracteres en un organismo. Los neodarwinistas más extremos plantean la teoría del "gen egoísta" según la cual, los genes están en constante competencia para poder transmitirse a las futuras generaciones. De esta forma se explicaría el proceso evolutivo: bajo esta visión se han desarrollado tecnologías como la medicina alopática, el uso de agrotóxicos para la agricultura, los organismos genéticamente modificados y otras nuevas tecnologías manipulantes de la vida; estas a su vez alteran los ciclos naturales y los procesos evolutivos. Es por

\footnotetext{
${ }^{7}$ Más información sobre los impactos de la nanotecnología pueden ser encontrados en /http://www.etcgroup.org/es/issues /nanotechnology $\rangle$.

${ }^{8}$ Por eso, un grupo de organizaciones internacionales interpusieron un juicio contra BP en las Cortes del Ecuador, haciendo uso del principio del derecho universal, por violación a los derechos de la naturaleza debido a este derrame. Más información en 〈http:/ / www.estudiosecologistas.org/index.php?option=com_content\&view=article\&id=41〉.

${ }^{9}$ Una revisión completa de cómo las teorías de Darwin han influenciado no solo a las ciencias biológicas, sino también a las sociales a lo largo de todo el siglo XX puede encontrarse en Castrodeza. 2009. La darwinización del mundo. Herder.
} 
ello, contradictorio enfrentar los derechos de la naturaleza desde el paradigma de la selección natural.

Los nuevos descubrimientos de la biología evolutiva cuestionan el sesgo ideológico que promueve la competencia y lucha por la supervivencia como mecanismo central de la evolución de las especies, y demuestran que la colaboración, la simbiosis, el mutualismo son los motores más importantes de la evolución ${ }^{10}$. Las nuevas tecnologías basadas en la sobrevivencia de los más fuertes son una amenaza a las múltiples relaciones mutualísticas que se dan en la naturaleza y, por lo mismo, impiden que los procesos evolutivos continúen.

\section{Conclusión}

Los derechos de la naturaleza surgen como una respuesta a una crisis ambiental que ha llevado inclusive a que algunos autores propongan que estamos frente a una nueva era geológica, el antropoceno; por los cambios que los sistemas económicos han producido en la estructura, los ciclos naturales y los procesos evolutivos de la naturaleza. Y nacen precisamente en una región del mundo que históricamente ha sido víctima de una economía de rapiña y sustentada con el fin de abastecer de materia prima a un puñado de países, en una lógica de colonialismo ambiental.

Estos derechos son abordados en la Constitución del Ecuador desde la perspectiva del Buen Vivir, es decir que se reconoce que los seres humanos tenemos derecho a hacer uso de los elementos naturales, de tal manera que se recupere un metabolismo con la naturaleza que respete sus ciclos de reproducción.

Debido a que los derechos de la naturaleza son de reciente reconocimiento, hay frente a nosotros un largo camino que recorrer tanto en el campo jurídico y epistemológico, como en el seno de la sociedad, pues la crisis ambiental demanda de alternativas reales para nosotros y para la naturaleza.

\section{Agradecimientos}

A la Escuela de Gestión para el Desarrollo Local Sustentable de la Universidad Politécnica Salesiana y al Instituto de Estudios Ecologistas del Tercer Mundo.

\section{Referencias}

Constitución de la República del Ecuador 2008.

Alimonda, H. 2012. Una introducción a la ecología política latinoamericana. En: Ecología política en el capitalismo contemporáneo, Programa Latinoamericano de Educación a Distancia, Centro Cultural de la Cooperación Floreal Gorini, Buenos Aires.

Crutzen, P. ¿Podremos sobrevivir al 'Antropoceno'? URL /http://www.ecoloquia.com /nuevo/index.php?option=com_content\&view =article\&id=3790:paul-j-crutzen-ipodremos -sobrevivir-al-antropoceno\&catid=103\&Itemid $=126$ ), acceso: enero 2013 .

Escobar, A. 2003. Mundos y conocimiento de otro mundo. Tabula Rasa, Bogotá, Colombia, págs. 5186.

Estermann, J. 1998. Filosofía Andina. Estudio intercultural de la sabiduría autóctona andina. Ediciones Abya Yala, Quito, pág. 359.

Fernández, R. 2012. El antropoceno: La crisis ecológica se hace mundial. URL $\langle$ www.rebelion.org/docs/104656.pdf $\rangle$, acceso: diciembre 2012.

Funes, R. 2009. Plantaciones esclavistas azucareras y transformación ecológica en cuba. Revista de Historia.

Luxemburgo, R. 1967. La acumulación de capital. Grijalbo, México.

Martínez, J. 2008. La crisis económica vista desde la economía ecológica. Ecología Política, 36: 23-32.

Muria, D. 2012. La naturaleza con derechos. Un recorrido por el derecho internacional de los derechos humanos, del ambiente y del desarrollo. Instituto de Estudios Ecologistas del Tercer Mundo, Quito.

Naredo, J. M. 2008. El conflicto entre eficacia y sostenibilidad: Utilizar el "capital mineral" de la tierra o el flujo solar y sus derivados renovables. Revista Polis, 21.

\footnotetext{
${ }^{10}$ Por ejemplo, la colonización vegetal del suelo fue posible gracias a la asociación que las plantas establecieron con hongos micorrizas.
} 
Porto Gonçalves, C. 2002. Da geografia as geografias: um mundo em busca de novas territorialidades. En: La guerra infinita. Hegemonía y terror mundial, págs. 217 -256, CLACSO.

Ruiz, M. 2012. Devastación ambiental y dependencia en américa latina: perspectiva desde el ecomarxismo.
Toledo, V. 2008. Metabolismos rurales: hacia una teoría económico-ecológica de la apropiación de la naturaleza. Revista Iberoamericana de Economía Ecológica, 7: 3.

Vitali, L. 1983. Hacia una historia del ambiente en América Latina. De las culturas aborígenes a la crisis ecológica actual. Nueva Sociedad. Editorial Nueva Imagen, México, pág. 46. 